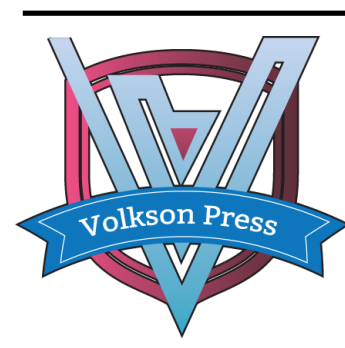

Contents List available at VOLKSON PRESS

New Materials and Intelligent Manufacturing (NMIM) DOI : http://doi.org/10.26480/icnmim.01.2018.187.190

Journal Homepage: https://topicsonchemeng.org.my/

ISBN: 978-1-948012-12-6

\title{
REVIEW ON THE PROGRESS IN THE SYNTHESIS OF ANTIHISTAMINES AND PROMETHAZINE
}

\author{
Dailin Li, Chuanbo Dai*, Yangyang Jiang \\ Institute of Petroleum and Chemical, Jilin Institute of Chemical Technology, Jilin City 132022, China \\ *Corresponding Author Email: daichb@163.com
}

This is an open access article distributed under the Creative Commons Attribution License, which permits unrestricted use, distribution, and reproduction in any medium, provided the original work is properly cited

\section{ARTICLE DETAILS}

\section{Article History:}

Received 26 June 2018 Accepted 2 July 2018

Available online 1 August 2018

\section{ABSTRACT}

In recent years, the development of antihistamines has become a popular research project and is still emphasized to the status of the treatment of allergic diseases. Many companies at home and abroad are working to develop better varieties to seize the pharmaceutical market. Because of antihistamine drugs plays an important role in the treatment of allergic diseases, are allergic rhinitis, urticaria, atomic dermatitis and other first-line drugs, so the size of the market is very considerable. As an antihistamine promethazine, the superiority of its low cost, as the use of veterinary drugs with new drug incomparable. This article comprehensively analyzed the effects of various antihistamines and the principle of their antihistamines and reviewed the synthesis routes of promethazine hydrochloride and its upstream product phenothiazine.

\section{KEYWORDS}

Histamine, Antihistamine, Promethazine hydrochloride.

\section{HISTAMINE AND ANTIHISTAMINES MECHANISM OF ACTION}

\subsection{Histamine}

It is part of the self-active substances. It is decarboxylation from histidine in the body and has a strong biological activity. Under normal conditions, histamine is kept in inactive, bound form in the mast cells and basophil granules of the tissue, and in the skin, bronchial mucosa, intestinal mucosa and nervous system [1-5]. When the body is subjected to physical and chemical stimulation or allergy occurs. These cells can cause degranulation, leading to histamine release. By binding to a specific histamine receptor on the target cell membrane, the receptor is directly agonized and various effects are produced [6,7]. Histamine receptors are well known for having three subtypes of $\mathrm{H}_{1}, \mathrm{H}_{2}$, and $\mathrm{H}_{3}$, and their distribution and effects. (e.g., Table 1,)

Table 1: Histamine Receptor Distribution and Effects Table

\begin{tabular}{|c|c|c|c|}
\hline Receptor type & Organization & Effectiveness & Antihistamines \\
\hline \multirow[t]{3}{*}{$\mathrm{H}_{1}$} & Bronchial gastrointestinal uterine smooth muscle & Shrink & $\begin{array}{l}\text { Diphenhydramine, } \\
\text { Promethazine, }\end{array}$ \\
\hline & Skin vessels & Expansion & Chlorpheniramine, etc. \\
\hline & Atria, atrioventricular node & $\begin{array}{l}\text { Contractility, conduction } \\
\text { slows }\end{array}$ & \\
\hline \multirow[t]{3}{*}{$\mathrm{H}_{2}$} & Gastric parietal cells & Secretion & Cimetidine. Ranitidine \\
\hline & Vascular & Expansion & \\
\hline & Ventricular and sinus node & Contractility, heart rate & \\
\hline \multirow[t]{2}{*}{$\mathrm{H}_{3}$} & Central and peripheral & $\begin{array}{l}\text { Negative } \\
\text { adjustment }\end{array}$ & Thiopropamide \\
\hline & Nerve endings & $\begin{array}{l}\text { Histamine } \\
\text { release }\end{array}$ & \\
\hline
\end{tabular}

\subsection{The mechanism of action of antihistamines}

Since antihistamines vary in their mechanism of action, they can be divided into histidine decarboxylase inhibitors, histamine $\mathrm{H}_{1}$ receptor antagonists, and histamine $\mathrm{H}_{2}$ receptor antagonists, of which $\mathrm{H}_{1}$ receptor antagonists are predominant [8-10]. The mechanism of action is mainly to block the $\mathrm{H}_{1}$ receptor. Because $\mathrm{H}_{1}$ receptor antagonists are highly selective for the $\mathrm{H}_{1}$ receptor, they can lock the binding of histamine at the $\mathrm{H}_{1}$ receptor at low concentrations.

\section{ROUTE SYNTHESIS OF PROMETHAZINE HYDROCHLORIDE}

Promethazine hydrochloride is also known as phenazine, promethazine, etc. Molecular formula: $\mathrm{C}_{17} \mathrm{H}_{20} \mathrm{~N}_{2} \mathrm{~S}$, melting point is $60^{\circ} \mathrm{C}$, boiling point is bp190 $192^{\circ} \mathrm{C}$, odorless white powder crystal. Slowly oxidizes in humid air and changes color when left for a long time. (e.g., Figure 1) 
<smiles>C[C@H](CN1c2ccccc2Sc2ccccc21)N(C)C</smiles>

Figure 1: Promethazine hydrochloride

In recent years, some of the major synthetic methods are the following:

Method 1:

The first method of synthesis developed in 1948 by Paul Charpentier, their 2-chloro - N, N- dimethyl isopropyl amine hydroiodide was dissolved in water and mixed with toluene. After the mixed solution was cooled added $50 \%$ concentration of aqueous sodium hydroxide solution, and stirred, several layers dried with a desiccant [11-15]. Was added dropwise with stirring a toluene solution of phenothiazine and sodium amide, in toluene at reflux the suspension for 2.5 hours, poured into water and the toluene layer was separated, and then poured into methanol mixture, methanol was added to dissolved solution of oxalic acid and sulfur urea, boiled, and then an alkali to give the appropriate oxalate promethazine to give promethazine [16]. (e.g., Figure 2)

This method is the first method of preparation of promethazine, tedious process and the conversion rate is not very high, but simple materials at that time, many of the improvements that we can learn from today.<smiles>CC(C)CN1c2ccccc2Sc2cc(C(C)C)ccc21</smiles>

Figure 2: Reaction of phenothiazine with 2-chloro-N, NDimethylisopropylamine hydroiodide to form promethazine

Method 2:

American scientist Samuel, Sidney, berg, who began the synthesis method promethazine improvements [17]. They first with anhydrous diethyl ether, methyl iodide and magnesium metal formed Grignard reagent was added thereto, and phenothiazine of anhydrous benzene, and the resulting solution was green mixture was reflexed for 30 minutes, and then added portentous over 1 hour 1-chloro 2-dimethylamino propane and anhydrous benzene solution, followed by continued reflux for 1.5 hours [18]. After cooling adding an appropriate amount of aqueous ammonium chloride, extracted with chloroform and then added, reservoir plus c (HCL) $=2 \mathrm{~mol} / \mathrm{L}$ aqueous solution, to give final promethazine hydrochloride. (e.g., Figure 3)

This method greatly increases the conversion rate of promethazine optimizes the process, due to the contaminated solvent which uses a large amount of chloroform and diethyl ether like, the discharged waste liquid will cause a lot of pollution.

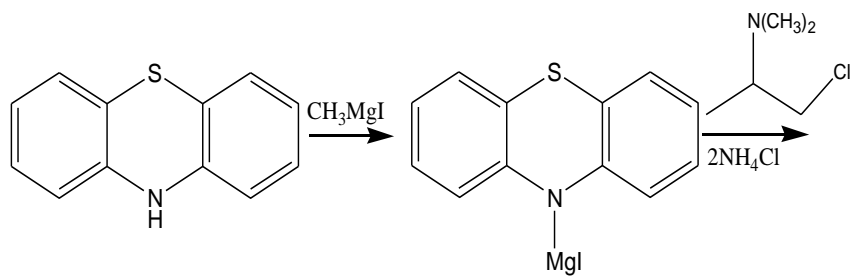

Figure 3: Adding phenothiazine to 1-chloro-2-dimethylaminopropane in Grignard reagent to prepare promethazine
Method 3:

Almost at the same time, Dahibom,J R.Aminalkyl and others found that the use of three bromide added to 10-(2-Carboxymethyl) thiophene of methylene chloride in response to the appropriate period, the 10-(2Bromo-propyl) thiophene, which is evaporated to dry, can be paralyzed by the copper powder and reacted with the dimethyl amine solution to produce the promethazine [19]. (e.g., Figure 4)

This method is improved by the raw material for the preparation of phenothiazine promethazine. Simple process is a new way of synthesis and improvement of promethazine.

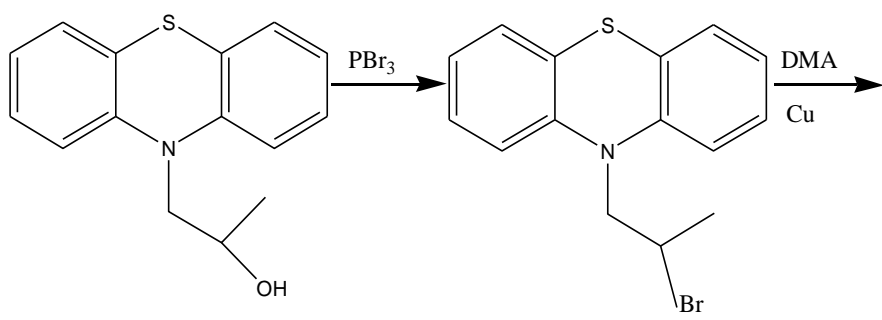

Figure 4: Phosphorus tribromide is added to the trichloromethane of 10Phenoxy phenothiazine to generate promethazine

Method 4:

Improved by the French company Rhone-Poulene Research 1953, phenothiazine dissolved in xylene was mixed with sodium amide. Refluxed for 3 hours, was added N, N- Dimethyl-P-Toluenesulfonyl MSDS and potassium carbonate, the aqueous layer was extracted with xylene oil layer were combined, dehydrated with sodium is heated for 20 minutes, the cooling water, the xylene layer was washed with concentration of $5 \%$ aqueous hydrochloric acid solution was separated, washed with an acetyl, and finally aqueous sodium hydroxide and with a concentration of 30 , to give the product promethazine. (e.g., Figure 5)

After the research results of thiophene, the synthesis of promethazine hydrochloride as a raw material is a common method in the process of synthesis of promethazine [20].<smiles>CC(C)CN1c2ccccc2Sc2ccc(C(N)C(C)C)cc21</smiles>

Figure 5: Phenothiazine is dissolved in xylene and mixed with sodium amide to add $\mathrm{N}, \mathrm{N}$-dimethyl $\mathrm{P}$-Toluenesulfonyl isopropylamine to promethazine

Method 5:

Rhone-Poulen Company again to improve the synthesis of promethazine, he used thiophene dissolved in $\mathrm{N}, \mathrm{N}$-two methyl formamide, and then in batches to add nah and mineral oil into the dispersion, and then cooled to $35{ }^{\circ} \mathrm{C}$ below, to maintain this temperature 1 hours later, Add a toluene solution of 2-two methyl P-Chloro propane and place the mixture until the heat is stopped to add methanol [21]. Then pour 1:1 of acetic acid and water, separate the toluene layer, discard after the layer with toluene washing, and then use sodium hydroxide to regulate acid-base to alkaline, that is, the promethazine. (e.g., Figure 6)

This is to Rhone-Poulen Company phenothiazine was synthesized as promethazine improved method, by changing the solvent, promethazine optimized synthetic route, an important idea promethazine later on improved synthetic route. 


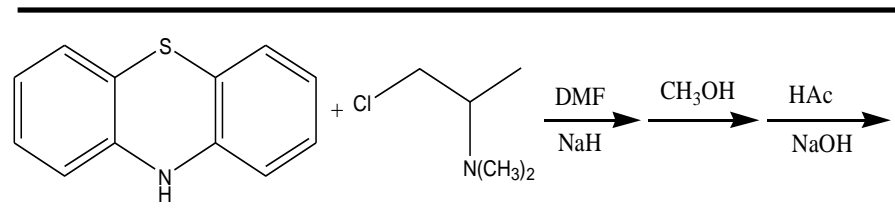

Figure 6: Phenothiazine is dissolved in N, N-Dimethylformamide to form promethazine

Method 6:

The method is a synthesis route of promethazine hydrochloride developed by Chinese scientists Wang Shuqin, Peng Jiagang, Yang Ruifen, etc [22-25]. It is to add diphenylamine and Potassium phthalate at $260^{\circ} \mathrm{C}$, and slowly adds 1-Ethoxy-2. The dimethyl carbonic acid ester was distilled under reduced pressure. The residue was separated with hydrochloric acid, and then alkalinity was adjusted with sodium hydroxide. After extracting with diethyl ether, the extract was distilled under reduced pressure and the obtained product was in an appropriate amount. The sulfur and iodine are mixed and brought to give the target promethazine. (e.g., Figure 7)

Instead of using the traditional phenothiazine as the main ring, this method uses diphenylamine as the main ring of promethazine [26]. First synthesizing its straight chain, and then modifying the main ring with sulfur. This synthetic route has a novel idea and strong innovation, and it has greatly improved both in terms of yield and reaction efficiency.

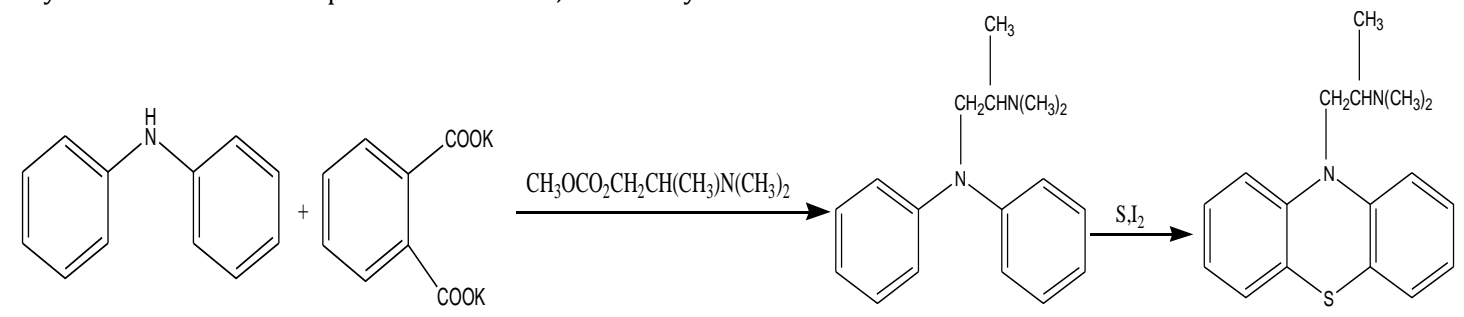

Figure 7: The reaction of diphenylamine with 1-Ethoxy-2-Dimethyl carbamate followed by the addition of sulfur produces promethazine hydrochloride

\section{SYNTHESIS ON PHENOTHIAZINE AS THE MAIN RING STRUCTURE OF PROMETHAZINE}

Phenothiazine, yellow to greenish gray powder or flaky crystals. Soluble in benzene, was dissolved in hot acetic acid and ether, slightly soluble in alcohol and mineral oil, almost insoluble in petroleum ether, chloroform and water [27]. The chemical formula is $\mathrm{C}_{12} \mathrm{H}_{9} \mathrm{~N}_{S}$, the melting point is 182$187^{\circ} \mathrm{C}$, the boiling point is $371^{\circ} \mathrm{C}$, and the density is 1.362 . (e.g., Figure 8). According to the different catalysts used, it is divided into several synthetic routes.<smiles>c1ccc2c(c1)Nc1ccccc1S2</smiles>

Figure 8: Phenothiazine structure

\subsection{Phenothiazine Synthesis Using $I_{2}$ as Catalyst}

Vasile et al used iodine as a catalyst for the reaction, and then used microwave radiation to heat the reaction between diphenylamine and sulfur [28]. Activation of electrons shortened the reaction time of the reaction, improved the efficiency, and achieved better yields. (e.g., Figure 9)<smiles>c1ccc(Nc2ccc(SCCSc3ccccc3Sc3ccccc3)cc2)cc1</smiles>

Figure 9: Using iodine as catalyst to react with elemental sulfur to produce phenothiazine

\subsection{Synthesis of Phenothiazine Using Pd as Catalyst}

This method is the earliest application of one-step coupling reaction to construct phenothiazines [29]. It was discovered by the scientist Jorgensen that the reaction used palladium as the catalyst to synthesize the target product. The operation steps of this reaction are relatively simple, but because Pd is more expensive, the method increases the cost of the synthesis reaction [30]. (e.g., Figure 10)<smiles>[NH3+]c1cc(-c2ccc3c(c2)Sc2ccccc2N3)ccc1Br</smiles>

Figure 10: Pd Catalyzed One-step Coupling Reaction for the Synthesis of Phenothiazine

\subsection{Synthesis of phenothiazine with $\mathrm{Cu}$ as catalyst}

Ma Dawei's research group reported that under the catalysis of $\mathrm{Cu} \mathrm{I} / \mathrm{L}-$ proline, raw materials 2-iodoaniline and 2-bromobenzenethiol were coupled by CS and CN to synthesize phenothiazine compounds [31]. In this synthetic route, there are two reaction centers where 2 -iodoaniline and 2 bromothiophenol can be couple, so the reaction is often accompanied by four possible products, two of which are from the raw materials themselves [32]. For coupling, there are for two products that are crosscoupled products. (e.g., Figure 11).<smiles>CC(C)(C)C(=O)c1ccc2c(c1)Sc1ccccc1N2</smiles>

Figure 11: Reaction of 2-Iodoaniline with 2-Bromothiophenol-copper Catalyzed Reaction to Produce Phenothiazine

\subsection{Phenothiazine Synthesis Using Fe as Catalyst}

Weiye $\mathrm{Hu}$ et al reports the synthesis of thiophene using $\mathrm{FeSO}_{4} \cdot 7 \mathrm{H}_{2} \mathrm{O}$ catalysts. The reaction was carried out using acetamidothiophenol and ortho-arylene dihalide as reactants, $\mathrm{t}-\mathrm{BuONa}$ as base for the reaction, and $\mathrm{DMF}$ as solvent in a nitrogen atmosphere at $135^{\circ} \mathrm{C}$ for $24 \mathrm{~h}$ to obtain the product [33]. This method is also used to synthesize phenothiazines through the coupling of C-S and C-N and replaces the conwentional copper and palladium catalysts with iron catalysts. The ubiquitous star is better, with the highest yield up to $96 \%$. However, when this method is utilized to synthesize phenothiazine, some substrates react to form two similar phenothiazine isomers, which are not easily separated. (e.g., Figure 12)

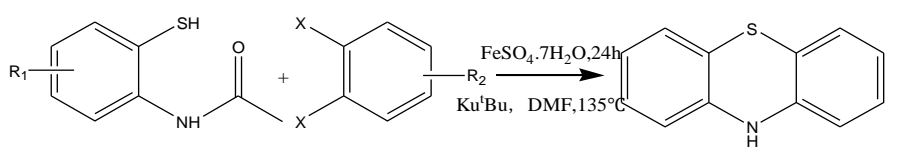

Figure 12: Fe catalyzes the reaction of acetamidothiophenol with orthoarylene dihalide to generate phenoxazine

\section{CONCLUSION}

Because the structure of promethazine is composed of a main ring and a branch, so in its process optimization is also mainly from these two structures to find the entry point, through the choice of different reagents, find the reaction conditions are more suitable The process path is simpler, the reaction rate is more efficient, and the reaction process is more environmentally friendly.

In the methods mentioned in this article, Method 1 and Method 2 both use phenothiazine as the main ring, and then the first form of a ring and then synthesize the branched chain. The synthetic route is clear and the process flow is simple, but because of relatively old technology, resulting in the 
production of product purity is not high, the yield is not very high these two routes; Method 3, Method 4 and Method 5 are improvements to the former, and in the same way that phenothiazine is also used as the main ring, the raw materials of its branches are Improvements have been made to increase the purity of the product, but due to the contamination of the waste liquid from the raw materials used, they are also very pure defects. Methods 6 are used in the synthetic route of promethazine hydrochloride a great innovation, it uses the first branched into a re-thinking of the ring, so that its stability during the reaction, and impurities less pure high, as an important breakthrough in the development of the synthetic routes of promethazine.

\section{ACKNOWLEDGMENTS}

I would like to thank my teacher, Professor Chuanbo Dai, for correcting my thesis and for his valuable suggestions. Thanks to the selfless dedication of the scientific research predecessors of the literature cited in this paper, it is your experience that leads me to continue.

\section{REFERENCES}

[1] Bond, R.A., IJzerman, A.P. 2006. Recent developments in constitutive receptor activity and inverse agonism, and their potential for GPCR drug discovery. Trends in Pharmacological Sciences, 27 (2), 92-96.

[2] Beale, J.M., Block, J.H. 2011. Wilson and Gisvold's Textbook of Organic Medicinal and Pharmaceutical Chemistry, 12th ed.; Wolters Kluwer, 733.

[3] Dahlbom, J. R.1952. Aminoalkyl Phenothiazine Swed. Pat. 134622, 0819.

[4] Xia, D., Lianjun, C. 2010. Application of antihistamines in the treatment of dermatological diseases [J]. Shanghai Pharmaceuticals, 31 (4), 153-155.

[5] Dahiya, S., Pathak, K., Sharma, R. 2008. Development of Extended Release Coevaporates and Coprecipitates of Promethazine $\mathrm{HCl}$ with Acrylic Polymers: Formulation Considerations. Chemical and Pharmaceutical Bulletin, 56 (4), 504-508.

[6] Hampel, F., Ratner, P., Diaz, J., Sacks, H. 2009. Efficacy a d safety of Azelastine hydrochloride and fluticasone propionate combined in a single nasal spray delivery device in patients with seasonal allergic rhinitis [J]. Journal Allergy Clinical Immunology, 123 (2), 155.

[7] Goodman, L.S., Gilman, A.G. 2006. Goodman and Gilman's, The Pharmacological Basis of Therapeutics, 11th ed.; McGraw Hill: New Delhi, 1884.

[8] Gopalaiah, K. 2013. Chiral Iron Catalysts for Asymmetric Synthesis. Chemical Reviews, 113 (5), 3248.

[9] Gildasio, S.A., Luciana, M.M.B., Fernanda, C.F.M., Ana, L.P., Eliezer, J., Carlos, A.M. 2004. New class of potent antinociceptive and antiplatelet $10 \mathrm{H}$-phenothiazine-1-acylhydrazone derivatives. Bioorganic \& Medicinal Chemistry, 12 (12), 3149-3158.

[10] International Centre for Diffraction Data (ICDD). 2012. Powder Diffraction File, PDF-4/Organics, ORGD120135-5045.

[11] Kavitha, K., Sandeep, D.S., Yadawad, M., Mangesh, M. 2011. Formulation and Evaluation of Oral Fast Dissolving Tablets of Promethazine $\mathrm{HCl}$ by Sublimation Method. International Journal of PharmTech Research, 3 (2), 660-663.

[12] Hongying, L., Zhiyong, X. 2008. The role of histamine receptors H1 and H4 in allergic inflammation: the study of new antihistamines [J]. Journal of International Pharmaceutical Research, 35 (4), 299-301.

[13] Ying, L., Min, Y., Lei, C. 2009. Cardiotoxicity of H1 antihistamines [J]. Chinese Journal of Clinical Immunology and Allergy, 3 (3), 196-202.

[14] Levi, C., Welsh, S.M., Phelps, K.V., Pilkiewicz, F.G.U.S. 2011. Patent US20110092493-A1.

[15] Lee, A.Y., Erdemir, D., Myerson, A.S. 2011. Crystal polymorphism in chemical process development. Annual Review of Chemical and Biomolecular Engineering, 2, 259-280.

[16] Mandhane, S.N., Ayer, U.B., Midha, A.S., Rao, C.T., Rajamannar, T. 2008.
Preclinical efficacy and safety pharmacology of SUN-1334H, a potent orally active antihistamine agent [J]. Drugs R D, 9 (2), 93-112.

[17] Montis, R., Hursthouse, M.B., Chan, H.C.S., Kendrickb, J., Leusen, F.J.J. 2012. Experimental and theoretical investigations of the polymorphism of 5-chloroacetoxybenzoic acid (5-chloroaspirin). CrystEngComm, 14, 16721680.

[18] Mayer, M., Lang, P.T., Gerber, S., Madrid, P.B., Pinto, I.G., Guy, R.K., James, T.L. 2006. Synthesis and testing of a focused phenothiazine library for binding to HIV-1 TAR RNA. Chemistry \& Biology, 13, 993.

[19] NicOx. 2005. NCX 1510 successfully achieves primary endpoint in clinical phase trial in rhinitis [EB/ OL]. http://www. nicox .com/ upload/ Biolipoxphase rhinitis results-English .pdf.

[20] Charpentier, P. 1950. Phenothiazines. US: 2530451, 11-21.

[21] Xiaolei, Q., Jinhua, X. 2008. A new understanding of histamine receptors and antihistamines [J]. Journal of Clinical Dermatology, 37 (3), 203-204.

[22] Poulenc, R. 1953. Phenothiazine Derivatives. Brit. 701741, 12-30.

[23] Poulenc, R. 1958. Phenothiazine Derivatives. Brit. 806676, 12-31.

[24] Simons, F.E. 2004. Advances in H1-antihistamines. The New England Journal of Medicine, 351 (21), 2203-2217.

[25] Samucl, Sidey, Berg. 1952. Processes for Preparing Phenothiazine Derivatives. US: 26077773, 08-19.

[26] Sailer, M., Franz, A.W., Mller, T.J.J. 2008. Synthesis and Electronic Properties of Monodisperse Oligophenothiazines. Chemistry - A European Journal, 14, 2602.

[27] Kasim, S., Omar, N.A., Akbar, N.S.M., Hassan, R., Jabar, M.A. 2017. Comparison Semantic Similarity Approach Using Biomedical Domain Dataset. Acta Electronica Malaysia, 1 (2), 1-4.

[28] Jiaxiang, W. 2008. Rational application of antihistamines [J]. China Practical Medicine, 3 (33), 174-175.

[29] Shuqin, W., Jiagang, P., Ruifen, Y. 1992. World Patent Preparation Method for Organic Drugs. Beijing: Science and Technology Literature Publishing House, 114.

[30] Wu, R.L., Anthes, J.C., Kreutner, W. 2004. Desloratadine inhibits constitutive and histamine-stimulated nuclear factor-kappaB activity consistent with inverse agonism at the histamine H1 Receptor. International Archives of Allergy and Immunology, 135 (4), 313-318.

[31] Wang, H.B., Wang, L., Shang, J.S., Li, X., Wang, H.Y., Gui, J., Lei, A.W. 2012. Chem. Commun. 48, 76.

[32] Keqin, X. 1998. Handbook of Fine Organic Chemical Raw Materials and Intermediates. Beijing: Chemical Industry Press, 4-121.

[33] Xiaomin, Z. 2009. Systematic evaluation of desloratadine in the treatment of chronic urticarial [J]. Chinese Journal of Evidence-based Medicine, 9 (7), 797.

\section{ABOUT THE AUTHORS}

Dailin Li (1993- ) graduated with a bachelor's degree in chemical engineering and technology from the Jilin Institute of Chemical Technology. He is now a graduate student in chemical engineering and technology at the Jilin Institute of Chemical Technology.

Professor Chuanbo Dai (1972-), the outstanding talent of the new century in Jilin Province, Jilin science and technology expert, Jilin City Youth Science and technology innovation and entrepreneurial talent, Jilin city science and technology innovation team leader, mainly engaged in the research work of chemical process development.

Yangyang Jiang (1992- ) graduated from Jilin Institute of Chemical Technology with a bachelor's degree in chemical engineering and technology. Now he is a graduate student of chemical engineering and technology in Jilin Institute of Chemical Technology. 